\title{
Quantification of the effect of an external magnetic field on water oxidation with cobalt oxide anodes
}

Camden Hunt, ${ }^{1,2}$ Zishuai Zhang, ${ }^{1}$ Karry Ocean, ${ }^{1}$ Ryan P. Jansonius, ${ }^{1}$ Mohamad Abbas, ${ }^{3}$ David J. Dvorak, ${ }^{2}$ Aiko Kurimoto, ${ }_{1}^{1}$ Eric W. Lees, ${ }^{3}$ Supriya Ghosh, ${ }^{6}$ Ari Turkiewicz, ${ }^{7}$ Felipe A. Garcés Pineda, ${ }^{8}$ David K. Fork, ${ }^{5}$ Curtis P. Berlinguette*1,2,3,4

${ }^{1}$ Department of Chemistry, The University of British Columbia, 2036 Main Mall, Vancouver, British Columbia, V6T 1Z1, Canada.

${ }^{2}$ Stewart Blusson Quantum Matter Institute, The University of British Columbia, 2355 East Mall, Vancouver, British Columbia, V6T 1Z4, Canada.

${ }^{3}$ Department of Chemical and Biological Engineering, The University of British Columbia, 2360 East Mall, Vancouver, British Columbia, V6T 1Z3, Canada.

${ }^{4}$ Canadian Institute for Advanced Research (CIFAR), 661 University Avenue, Toronto, Ontario, M5G 1M1, Canada.

${ }^{5}$ Google LLC., 1600 Amphitheatre Parkway, Mountain View, CA, 94043 USA.

${ }^{6}$ Department of Chemistry, University of Pittsburgh, Pittsburgh, PA, 15260, USA.

${ }^{7}$ Department of Chemistry, University of California, Berkeley, CA, 94720, USA.

${ }^{8}$ Institute of Chemical Research of Catalonia (ICIQ), The Barcelona Institute of Science and Technology (BIST), Tarragona, Spain. 


\section{S1. Materials and Methods}

General: All voltage and current conventions follow IUPAC standards. All potentials are reported versus the normal hydrogen electrode (NHE) using the following relation to convert the potential measured using a leakless $\mathrm{Ag} / \mathrm{AgCl}$ reference electrode:

$$
E_{N H E}=E_{A g / A g C l}^{0}+E_{A g / A g C l}
$$

With $E^{0}{ }_{\mathrm{Ag} / \mathrm{AgCl}}$ assumed as $0.198 \mathrm{~V}^{1}$. A Metrohm AG Autolab PGSTAT302N was used for all electrochemical measurements. The cell temperature for all measurements was measured using a digital thermometer with a teflon-coated tip inserted directly into the solution at the start and end of each experiment. The uncompensated resistance $\left(R_{u}\right)$ was measured by the current interrupt method, and was typically $\sim 15-20 \Omega$ for all experiments unless otherwise noted. IR correction was applied post-data collection based on $R_{u}$ as suggested by Boettcher ${ }^{2}$ and $\mathrm{Kundu}^{3}$. Galvanostatic experiments are reported with no IR correction, as has been suggested for the evaluation of any electrocatalyst ${ }^{3}$. All current densities are calculated based on the measured electrochemical surface area (ECSA). The roughness factor (i.e., $S A_{\text {electochemical }} S A_{\text {geometric }}$ ) for the $\mathrm{CoO}_{\mathrm{x}}$ surface is approximately $\sim 1.0$ as determined from ECSA measurements, consistent with the smooth morphology observed by SEM. Steel alligator clips were used for all connections between electrodes and potentiostat leads. The magnet used for all experiments was a $2.54 \times 2.54 \times 1.27 \mathrm{~cm} \mathrm{NdFeB}(\mathrm{ND} 52$ grade) neodymium magnet obtained from K\&J Magnetic Inc. (BX0X08-N52). Surface resistance measurements on the FTO substrate were performed using a Commercial Electric multimeter (MMM-8301-S).

Apparatus: The apparatus used for all electrochemical measurements consisted of a metal base with a Zaber linear actuator (LC40B530) and custom cell stand screwed into the metal base. The custom cell was 3D-printed from Formlabs Clear Resin on a Form 3 SLA printer. The cell was affixed to the custom stand with screws. A custom 3D-printed holder for the ND52 magnetic was installed on the linear actuator. The motor step speed, step size, and positioning were monitored and controlled using the Zaber console inhouse software (Version 2.6.8.443).

Reagents: $\mathrm{CoCl}_{2} \cdot 6 \mathrm{H}_{2} \mathrm{O}$ was purchased from Sigma Aldrich. Tartaric acid $\left(\mathrm{C}_{4} \mathrm{H}_{6} \mathrm{O}_{6}\right)$ from Sigma Aldrich. $\mathrm{NaHCO}_{3}$ was obtained from Sigma Aldrich. $\mathrm{KPF}_{6}$ was obtained from Sigma Aldrich, and recrystallized from water prior to use. Acetonitrile was obtained from Sigma Aldrich and stored over activated $3 \AA$ molecular sieves. $\mathrm{KOH}$ purchased from Sigma-Aldrich. Milli-Q water was used for the preparation of all solutions unless otherwise noted. FTO plates were obtained from Sigma Aldrich. A 0.1 M KOH solution 
$\left(\mathrm{pH}_{\text {measured }}=12.75\right)$ was stored in a sealed, opaque HDPE bottle. The $\mathrm{pH}$ of these solutions was measured after preparation using a pH meter (Mettler Toledo SevenCompact S220) which was calibrated against a set of acidic $(\mathrm{pH}=4)$, neutral $(\mathrm{pH}=7)$, and basic $(\mathrm{pH}=10)$ standards before each use. Deposition solutions were prepared fresh for each deposition. All reagents were used without further purification unless otherwise noted.

$\mathrm{CoO}_{x} \mid$ FTO working electrode preparation: The $\mathrm{CoO}_{\mathrm{x}} \mid \mathrm{FTO}$ electrodes were prepared by electrochemical deposition of $\mathrm{Co}$ (II) onto a $2 \times 2 \times 0.23 \mathrm{~cm}$ FTO substrate $\left(R_{\text {surface }} \cong 20 \Omega \cdot \mathrm{cm}^{-2}\right)$. Copper tape was placed on the top of the FTO substrate and the surface was partially masked with Kapton tape to provide a $2 \times$ $0.5 \mathrm{~cm}$ area exposed to the deposition stock solution. The deposition stock solution consisted of $0.8 \mathrm{mmol}$ $\mathrm{C}_{4} \mathrm{H}_{6} \mathrm{O}_{6}, 0.08 \mathrm{mmol}$ of $\mathrm{CoCl}_{2} \cdot 6 \mathrm{H}_{2} \mathrm{O}$, and $2 \mathrm{mmol}$ of $\mathrm{NaHCO}_{3}$ in $60 \mathrm{~mL}$ of Milli-Q water. $\mathrm{CoO}_{\mathrm{x}}$ deposition was performed galvanostatically at $50 \mu \mathrm{A}$ for the thin samples $\left(\mathrm{CoO}_{\mathrm{x}} \mid \mathrm{FTO}_{\text {thin }} ; V_{S S} \cong 0.98 \mathrm{~V} \mathrm{vs}\right.$. $\left.\mathrm{Ag} / \mathrm{AgCl}\right)$ and $250 \mu \mathrm{A}$ for the thick samples $\left(\mathrm{CoO}_{\mathrm{x}} \mid \mathrm{FTO}_{\text {thick}} ; V_{S S} \cong 1.35 \mathrm{~V}\right.$ vs. $\left.\mathrm{Ag} / \mathrm{AgCl}\right)$ for $30 \mathrm{~min}$. The resulting film was yellow/green.

$\mathrm{CoO}_{x} \mid$ FTO anodization: Anodization was performed following a modification of a procedure reported by $\mathrm{Ghosh}^{4}$. The $\mathrm{CoO}_{\mathrm{x}} \mid \mathrm{FTO}$ working electrode was immersed in $0.1 \mathrm{M} \mathrm{KOH}$ with a Pt counter electrode and a leakless $\mathrm{Ag} / \mathrm{AgCl}$ reference electrode, and potentiostatically anodized in a 3-step procedure with each step held for $20 \mathrm{~min}$. The film darkened during anodization, but upon removal from the cell reverted back to the original yellow/green color in $\sim 5 \mathrm{~min}$.

Pt counter electrode preparation: A Pt wire with a Pt mesh affixed to the end of the wire was used as the counter electrode. The electrode was cleaned with Milli-Q water and heated white-hot with a propane torch prior to use.

Leakless $\mathrm{Ag} / \mathrm{AgCl}$ reference electrode preparation: A leak-free $\mathrm{Ag} / \mathrm{AgCl}$ reference electrode using a leakless junction (eDAQ ET072) was used for all electrochemical measurements. The electrode was rinsed with Milli-Q water prior to use and referenced vs. a $4.0 \mathrm{M} \mathrm{KCl}$ glass-body $\mathrm{Ag} / \mathrm{AgCl}$ master reference electrode (Fisher Scientific 13-620-53) by measuring the open-circuit potential between both electrodes in a saturated $\mathrm{KCl}$ solution. The master electrode was stored in a saturated $\mathrm{KCl}$ solution when not in use. $X$-ray diffraction (XRD) measurements: XRD measurements were performed on the $\mathrm{CoO}_{\mathrm{x}} \mid \mathrm{FTO}$ anode using a Rigaku Smartlab diffractometer. The measurements were taken in grazing incidence using parallel beam optics and $\mathrm{Cu} \mathrm{K} \alpha$ radiation. Data was collected between $2 \theta$ angles of $20^{\circ}$ and $80^{\circ}$ with a step size of $0.05^{\circ}$ and a fixed incidence angle of $1^{\circ}$. The scan rate was $0.5^{\circ} \cdot \mathrm{min}^{-1}$.

Ultraviolet-visible (UV-Vis) and circular dichroism (CD) spectroscopy measurements: UV-Vis and CD measurements were performed on the $\mathrm{CoO}_{\mathrm{x}} \mid \mathrm{FTO}$ anode using a Jasco J-815 spectrometer. All 
measurements were performed at room temperature with the sample perpendicular to the light path. A bare FTO glass plate was used as the baseline measurement.

Fourier transform infrared (FTIR) spectroscopy: The FTIR spectra were measured by a PerkinElmer Frontier FTIR spectrometer with a UATR attachment and $\mathrm{C}_{\text {diamond}} / \mathrm{ZnSe}$ top plate. The top plate was cleaned with ethanol prior to use. The sample film was compressed on the crystal to ensure sufficient contact.

$X$-ray fluorescence $(X R F)$ microscopy measurements: A hyperspectral X-ray fluorescence (XRF) image of the $\mathrm{CoO}_{\mathrm{x}} \mid \mathrm{FTO}$ anode was taken using a Bruker M4 TORNADO X-ray fluorescence microscope. The XRF microscope has a rhodium X-ray source operated at $50 \mathrm{kV} / 600 \mu \mathrm{A} / 30 \mathrm{~W}$ and polycapillary X-ray optics yielding a $25 \mu \mathrm{m}$ spot size on the sample. The instrument employs twin $30 \mathrm{~mm}^{2}$ silicon SSD detectors and achieves an energy resolution of $10 \mathrm{eV}$. Hyperspectral images were taken over a $43.6 \mathrm{~mm}$ $\times 13.7 \mathrm{~mm}$ area at a resolution of $1300 \times 408$ pixels. The instrument generates a peak at exactly zero energy which is used for energy calibration. Each point measurement was integrated for $100 \mathrm{~ms}$. The spectral energy is binned at $10 \mathrm{eV}$. Spectra was acquired from 0 to $40 \mathrm{keV}$. The resulting spectra was integrated over the following ranges: $\mathrm{Co}$ : 6.80 to $7.05 \mathrm{keV}(\mathrm{K} \alpha)$;. The colour scale was manually set to a maximum of $1000 \mathrm{cps}$ for visualization purposes.

Scanning electron microscopy (SEM) measurements: SEM images of the $\mathrm{CoO}_{\mathrm{x}}$ films were collected using a Helios NanoLab 650 microscope at accelerating voltages of 5 and $10 \mathrm{kV}$ and a beam current of $50 \mathrm{pA}$. Cross-sectional images were obtained by cleaving the $\mathrm{CoO}_{\mathrm{x}} \mid$ FTO sample and imaging the freshly broken edges.

Estimation of $\mathrm{CoO}_{x}$ crystallite size from XRD: The $\mathrm{CoO}_{\mathrm{x}}$ crystallite size for the deposited films was estimated via a Scherrer analysis of the XRD spectrum (Figure S4). The XRD data was smoothed, baseline subtracted, and the peaks were identified and fit using Origin ${ }^{\circledR}$ Pro 2019. The mean crystallite size for the $\mathrm{CoO}_{\mathrm{x}}$ film was calculated using the Sherrer equation:

$$
\tau=K \lambda /(\beta \cos (\theta))
$$

Where $\tau$ is the mean crystallite size in $\AA, K$ is the dimensionless shape factor $(0.9), \lambda$ is the $\mathrm{X}$-ray

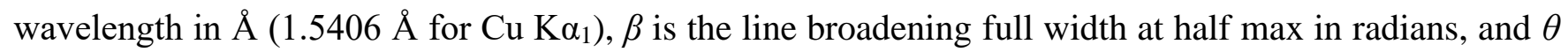
is the Bragg angle in radians.

Electrochemical surface area (ECSA) determination: ECSA measurements were performed on the $\mathrm{CoO}_{\mathrm{x}} \mid$ FTO working electrode in $\mathrm{CH}_{3} \mathrm{CN}$ with $0.15 \mathrm{M} \mathrm{KPF}_{6}$ following a methodology reported by 
Surendranath $^{5}$. A value of $11 \pm 5 \mathrm{uF} \mathrm{cm}^{-2}$ was assumed as the areal capacitance $\left(C_{s}\right)$ for the $\mathrm{CoO}_{\mathrm{x}}$ working electrode. A series of small $(50 \mathrm{mV})$ window cyclic voltammograms were recorded, with the start and end of each sweep centered on the open-circuit potential (OCP). The difference in the anodic and cathodic current $\left(i_{a}-i_{c}\right)$ at the OCP was plotted as a function of the scan rate $(s r)$, and the slope of the linear fit of $i_{a}-i_{c}$ vs. $s r$ is equal to twice the double-layer capacitance $\left(C_{d l}\right) . C_{d l}$ was subsequently divided by $C_{s}$ to obtain the ECSA.

Cyclic voltammetry $(C V)$ measurements: $\mathrm{CV}$ measurements were performed on the $\mathrm{CoO}_{\mathrm{x}} \mid \mathrm{FTO}$ working electrode in 0.1 M KOH with a Pt mesh counter electrode and a leakless $\mathrm{Ag} / \mathrm{AgCl}$ reference electrode. All measurements were performed under an argon atmosphere. All scan rate series feature a recursive scan that is performed at the same scan rate as the first scan. This is done to verify the fidelity of the working electrode throughout the scan rate series. No IR correction was applied for the measurements.

Tafel measurements: Tafel measurements were performed using staircase chronoamperometry for different values of $\beta_{\text {anode }}$. The sequence for chronoamperometry was: i) Polarization of the $\mathrm{CoO}_{\mathrm{x}} \mid \mathrm{FTO}$ anode at a potential of $1.32 \mathrm{~V}$ for $60 \mathrm{~s}$; ii) a voltage step sequence of $\sim 0.04 \mathrm{~V}$ from $1.32 \mathrm{~V}$ to $1.475 \mathrm{~V}$, with each step held for $5 \mathrm{~s}$; iii) a recursive step back down to $1.32 \mathrm{~V}$ to verify that exfoliation during the polarization procedure was minimal; iv) a $5 \mathrm{~s}$ wait period to adjust the magnet position. This method (Figure S19) was shown to be capable of accommodating the delayed onset of the magnetic enhancement while also mitigating exfoliation of the $\mathrm{CoO}_{\mathrm{x}} \mid \mathrm{FTO}$ anode.

Superconducting quantum interference device (SQUID) magnetometry: SQUID was performed on $\mathrm{CoO}_{\mathrm{x}}$ material that was prepared using long electrodeposition times with the same electrochemical conditions as described above. The thick, dark $\mathrm{CoO}_{\mathrm{x}}$ films were washed with DI water, and allowed to dry, which resulted in cracking and flaking of a crystalline material that was collected. The dry material was collected, mixed with eicosane wax, and placed in a gel capsule for data collection. A field sweep of $\pm 5 \mathrm{~T}$ was used for all measurements. All measurements were performed at room temperature.

Inductively coupled plasma optical emission spectroscopy (ICP-OES): ICP-OES was performed using a series of $\mathrm{Co}^{\mathrm{n}+}$ standards prepared from $\mathrm{CoCl}_{2} \cdot 6 \mathrm{H}_{2} \mathrm{O}$ in DI water. DI water was used in lieu of $0.1 \mathrm{M} \mathrm{KOH}$ due to the immediate precipitation of $\mathrm{Co}^{\mathrm{n}+}$ salts from basic solutions. The calibration series consisted of 0, 1, 10, 100, $1000 \mathrm{ppm} \mathrm{Co}^{2+}$ standards. The sample consisted of $0.1 \mathrm{M} \mathrm{KOH}$ electrolyte after $1 \mathrm{~h}$ of electrolysis at $50 \mathrm{~mA} \cdot \mathrm{cm}^{-2}$.

Atmospheric mass spectrometry (atm-MS): An ESS CatalySys atmospheric mass spectrometer was used for oxygen detection experiments. A CoO $\mathrm{C}_{\mathrm{x}} \mathrm{FTO}$ anode was subjected to $50 \mathrm{~mA} \cdot \mathrm{cm}^{-2}$ in $0.1 \mathrm{M} \mathrm{KOH}$, with constant stirring in the 3D-printed cell. The production of gaseous $\mathrm{O}_{2}$ in the cell was monitored by atm- 
MS by sampling the headspace of the cell. The $\mathrm{O}_{2}$ peak taken as $\mathrm{m} / \mathrm{z}=16$. An intake rate of $10 \mathrm{~mL} \cdot \mathrm{min}^{-}$ ${ }^{1}$ was used.

Finite element analysis (FEA) magnetic model: The finite element analysis (FEA) model used in this work was created using COMSOL MultiPhysics 5.5. The magnetic field can be described by the magnetic flux density and the magnetic field intensity (denoted as $\boldsymbol{B}$ and $\boldsymbol{H}$, respectively) for each point in space. By assuming the absence of currents and time-dependent effects, we can reduce these relations to their most general form, Gauss's law for magnetism, and the Ampere-Maxwell law, respectively.

$$
\begin{aligned}
& \nabla \cdot B=0 \\
& \nabla \cdot H=0
\end{aligned}
$$

In other words, we can say that there is no net flow of magnetic field across any closed surface, and by extension, the absence of magnetic monopoles. The latter equation implies that the scalar potential can be defined from the relation:

$$
H=-\nabla V_{m}
$$

Thus, taking $V_{m}$ as the dependent variable, we can ultimately solve for the problem of magnetostatics. Coupling the above equation with the constitutive relation:

$$
B=\mu_{0} \mu_{r e c} H+B_{r}
$$

Gauss's law for magnetism can be rewritten as:

$$
-\nabla\left(\mu_{0} \mu_{r e c} V_{m}+B_{r}\right)=0
$$

Where $\mu_{0}$ and $\mu_{r e c}$ are the relative and recoil permeabilities, respectively, and $B_{r}$ is the remanent flux density. 


\section{S2. Figures}

a)

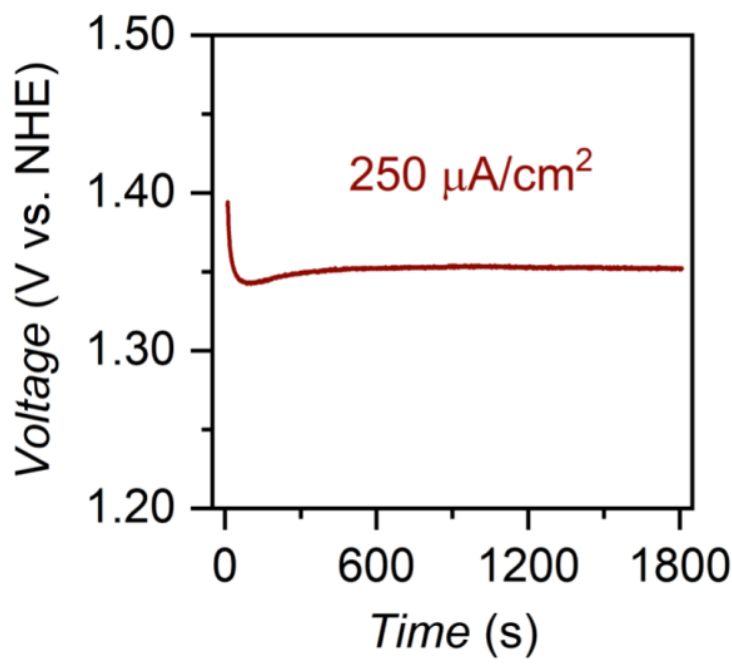

b)

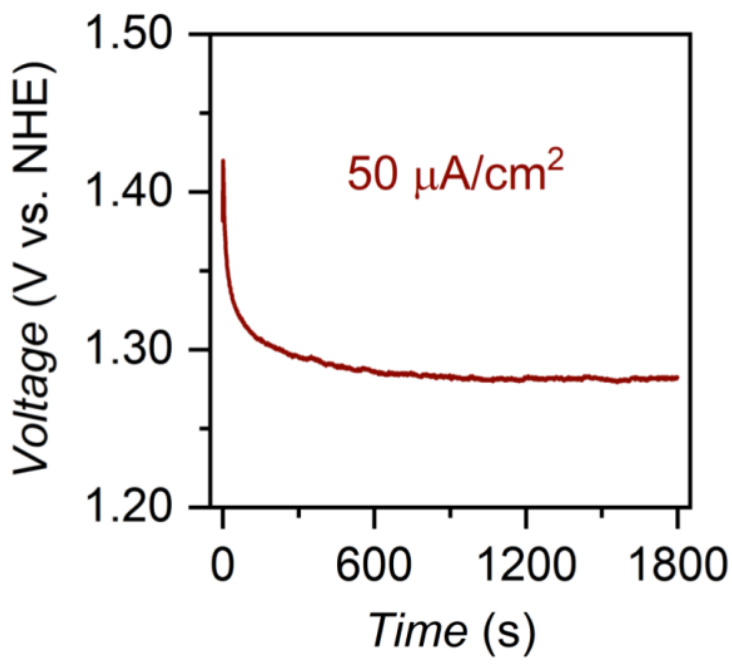

Figure S1. Galvanostatic electrodeposition of $\mathrm{CoO}_{\mathrm{x}}$ onto an FTO substrate for (a) the $\mathrm{CoO}_{\mathrm{x}} \mid \mathrm{FTO}_{\text {thick }}$ anode and (b) the $\mathrm{CoO}_{\mathrm{x}} \mid \mathrm{FTO}_{\text {thin }}$ anode. The deposition solution consisted of $0.8 \mathrm{mmol}$ of tartaric acid, $0.08 \mathrm{mmol}$ of $\mathrm{CoCl}_{2} \cdot 6 \mathrm{H}_{2} \mathrm{O}$, and $2 \mathrm{mmol}$ of $\mathrm{NaHCO}_{3}$ in $60 \mathrm{~mL}$ of Milli-Q water. The uncompensated resistance $\left(R_{u}\right)$ for both samples was $\sim 30 \Omega$.

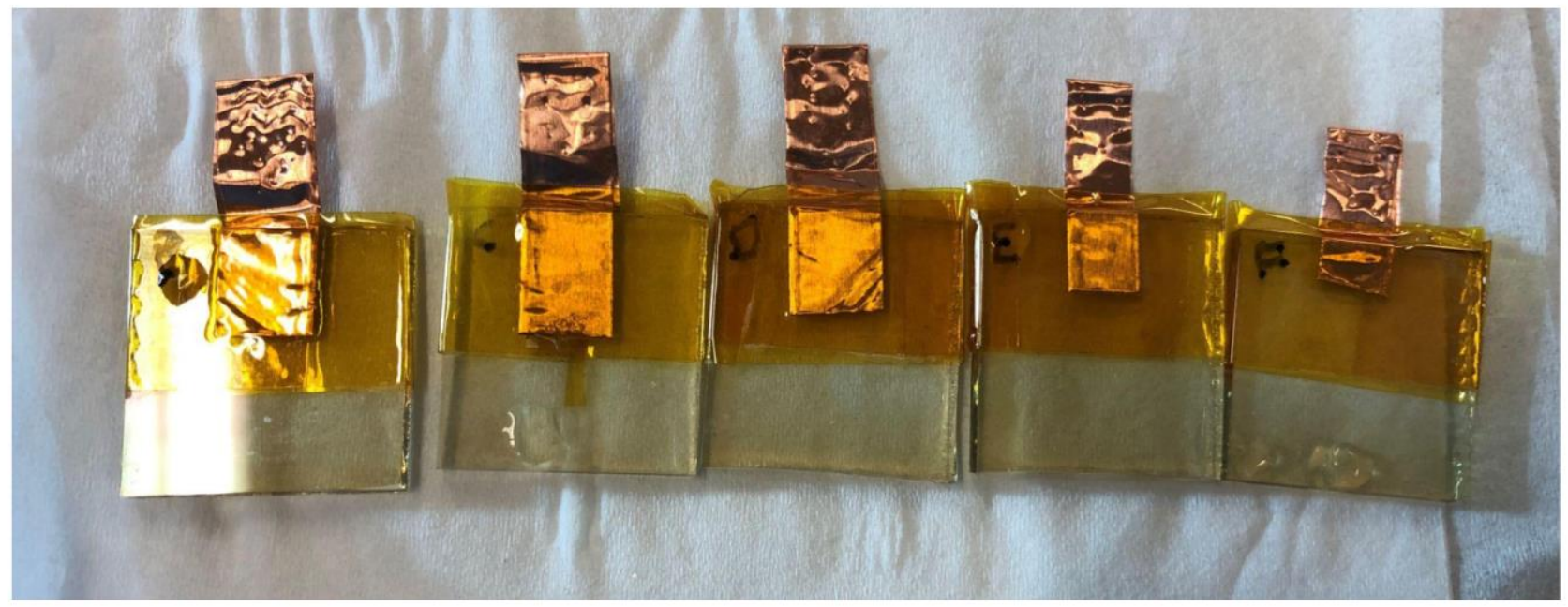

Figure S2. The $\mathrm{CoO}_{\mathrm{x}} \mid \mathrm{FTO}$ films after electrodeposition. 
a)

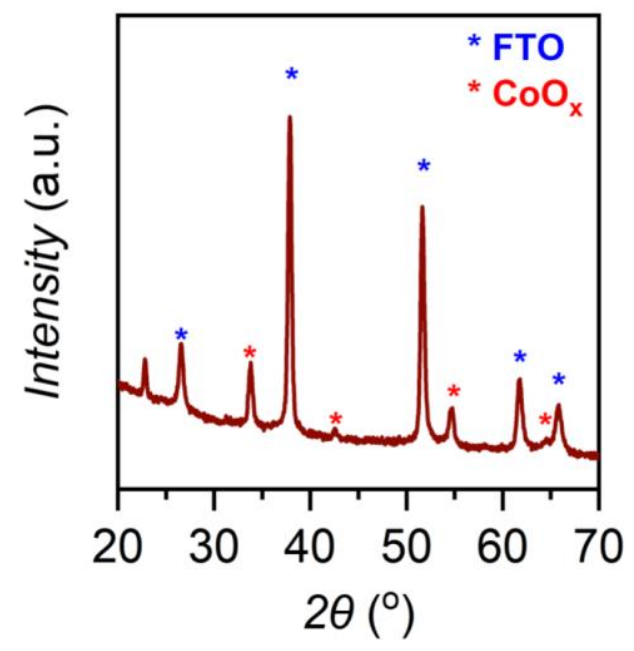

b)

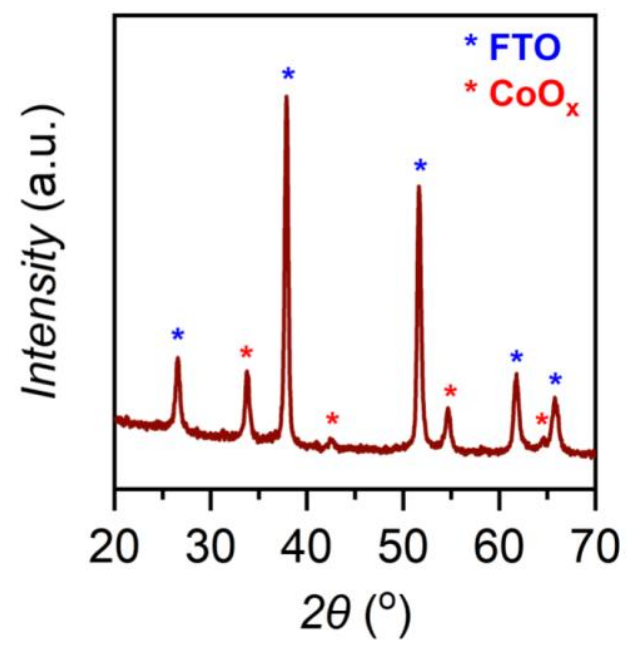

Figure S3. The X-ray diffraction pattern of (a) the $\mathrm{CoO}_{\mathrm{x}} \mid \mathrm{FTO}_{\text {thick }}$ anode and (b) the $\mathrm{CoO}_{\mathrm{x}} \mid \mathrm{FTO}_{\text {thin }}$ anode. The peak at $2 \theta \cong 23^{\circ}$ for $\mathrm{CoO}_{\mathrm{x}} \mid \mathrm{FTO}_{\text {thick }}$ is unidentified.

a)

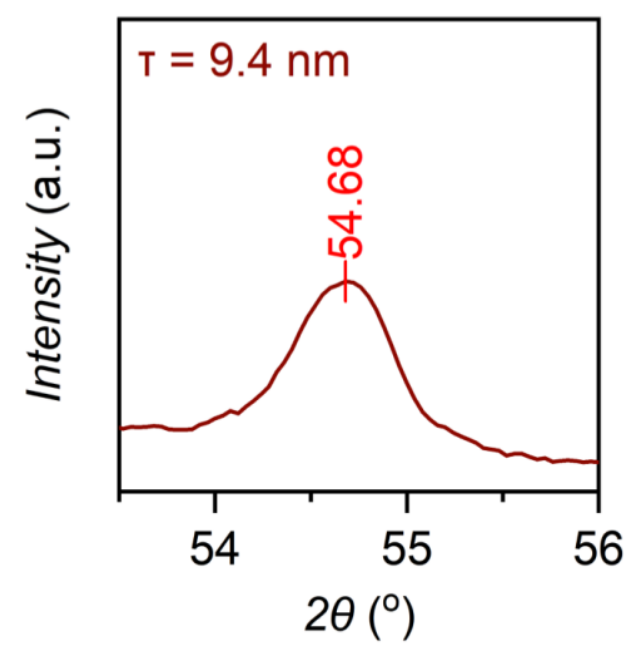

b)

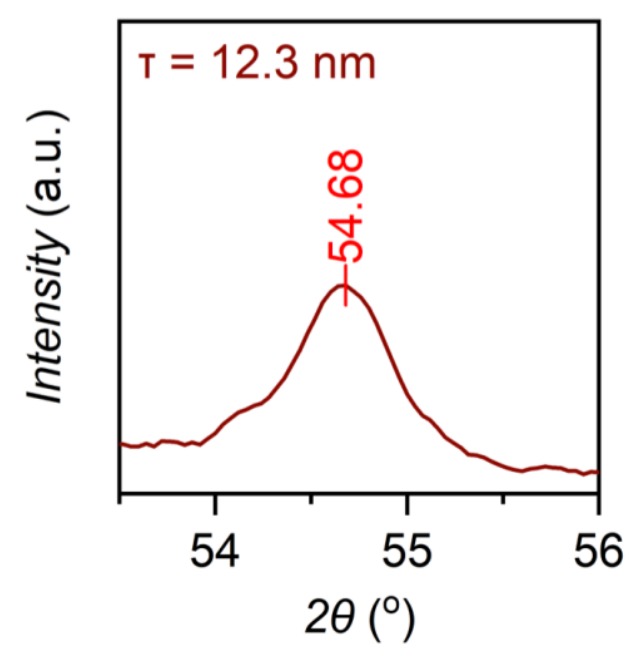

Figure S4. The Bragg peak used to perform the Scherrer analysis for (a) the $\mathrm{CoO}_{\mathrm{x}} \mid \mathrm{FTO}_{\text {thick }}$ anode and (b) the $\mathrm{CoO}_{\mathrm{x}} \mid \mathrm{FTO}_{\text {thin }}$ anode. The calculated mean crystallite size $(\tau)$ is in the upper inset. 
a)

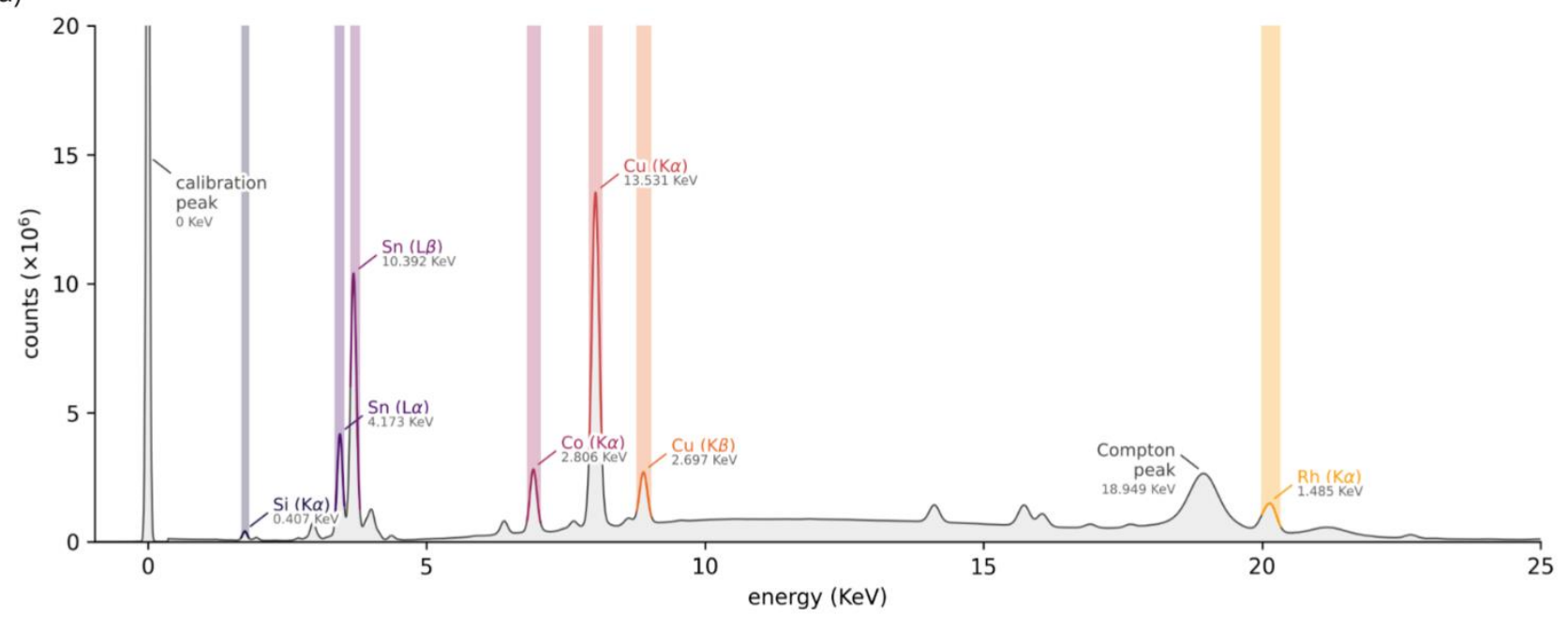

b)
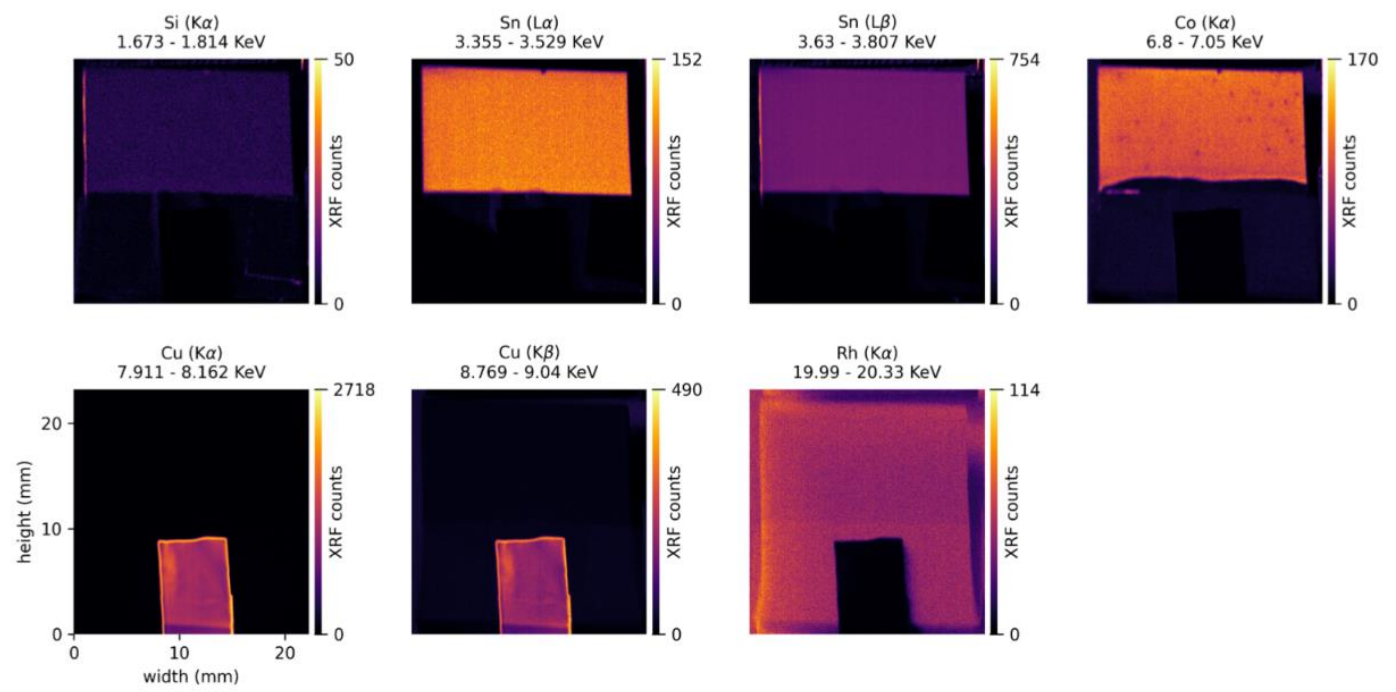

Figure S5. (a) The comprehensive XRF spectrum of the $\mathrm{CoO}_{\mathrm{x}} \mid \mathrm{FTO}$ anode from $0-25 \mathrm{keV}$. (b) The XRF spatial map of the dominant elements in the films. The $1.485 \mathrm{keV}(\mathrm{K} \alpha)$ peak is an artifact from the $\mathrm{Rh}$ source. 
a)

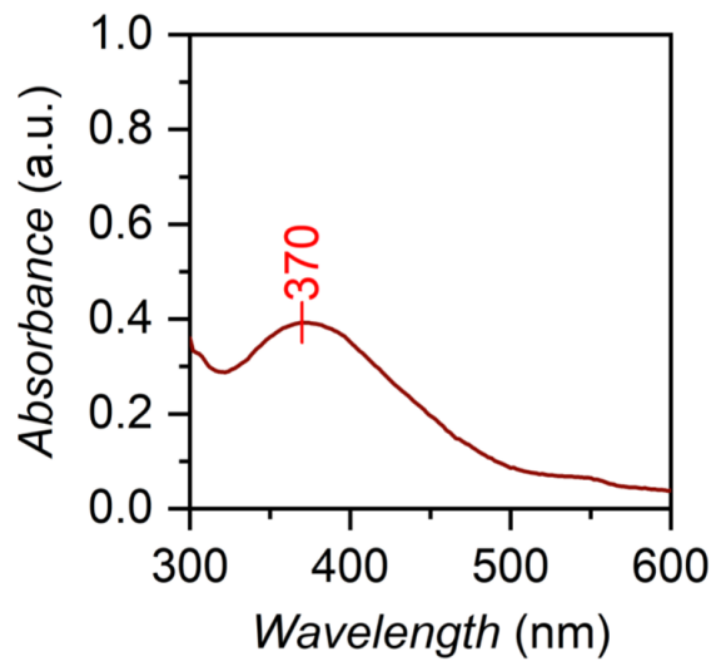

b)

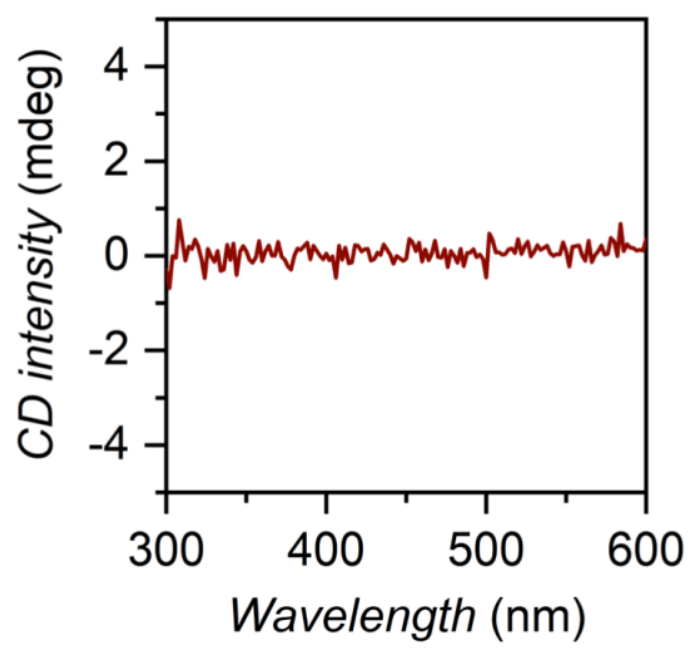

Figure S6. The UV-Vis (a) and CD spectra (b) for the $\mathrm{CoO}_{\mathrm{x}} \mid \mathrm{FTO}$ anode. A blank FTO plate was used as the baseline for both measurements.

a)

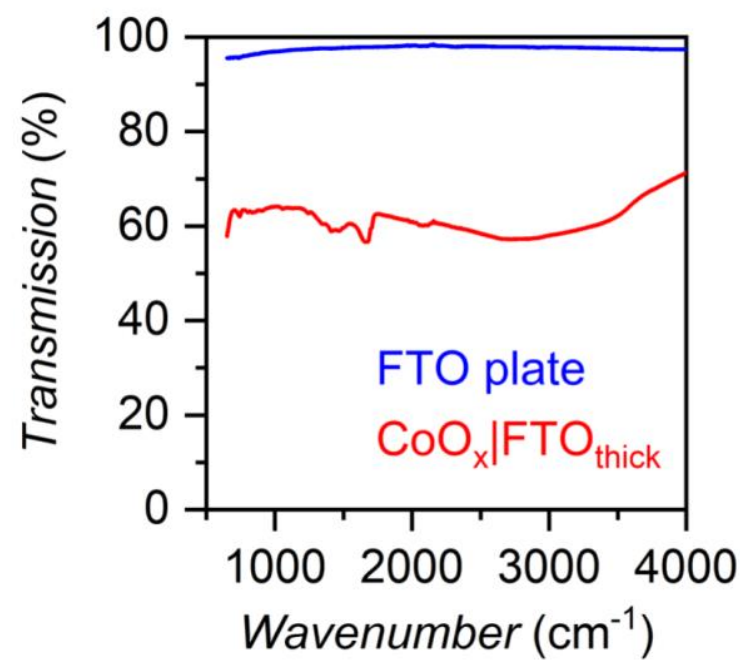

b)

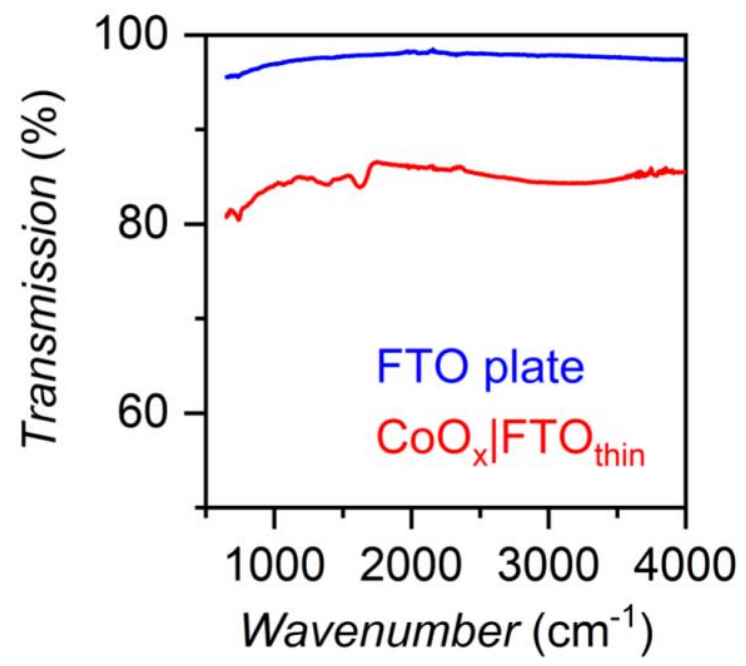

Figure S7. Fourier-transform infrared (FTIR) spectra of (a) the $\mathrm{CoO}_{\mathrm{x}} \mid \mathrm{FTO}_{\text {thick }}$ anode (red) and (b) the $\mathrm{CoO}_{\mathrm{x}} \mid \mathrm{FTO}_{\text {thin }}$ anode (red), and the bare FTO substrate (blue). 


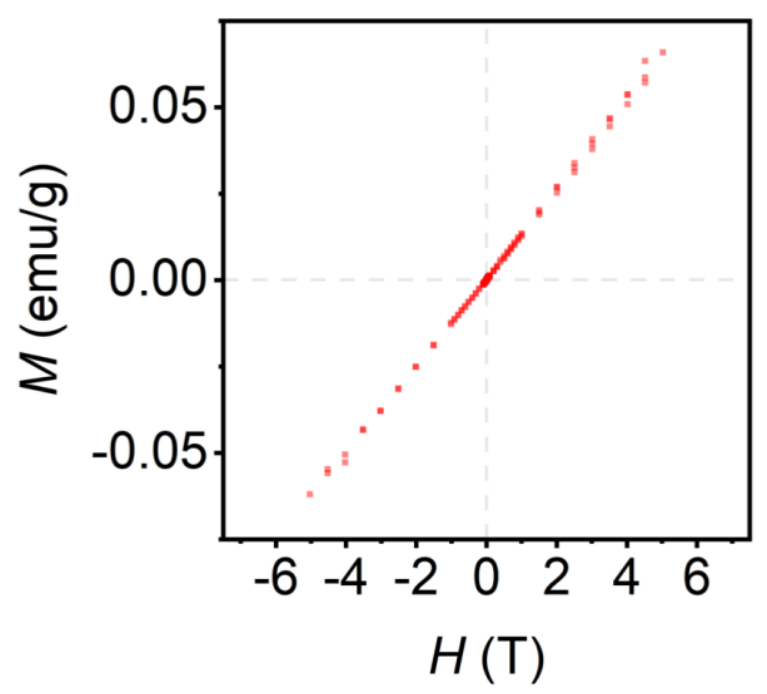

Figure S8. Superconducting quantum interference device (SQUID) magnetometry data collected on 5.1 mg of electrodeposited $\mathrm{CoO}_{\mathrm{x}}$ material with a field sweep of $\pm 5 \mathrm{~T}\left(3.4 \mathrm{mT} \cdot \mathrm{s}^{-1}\right)$ at $298 \mathrm{~K}$.

a)

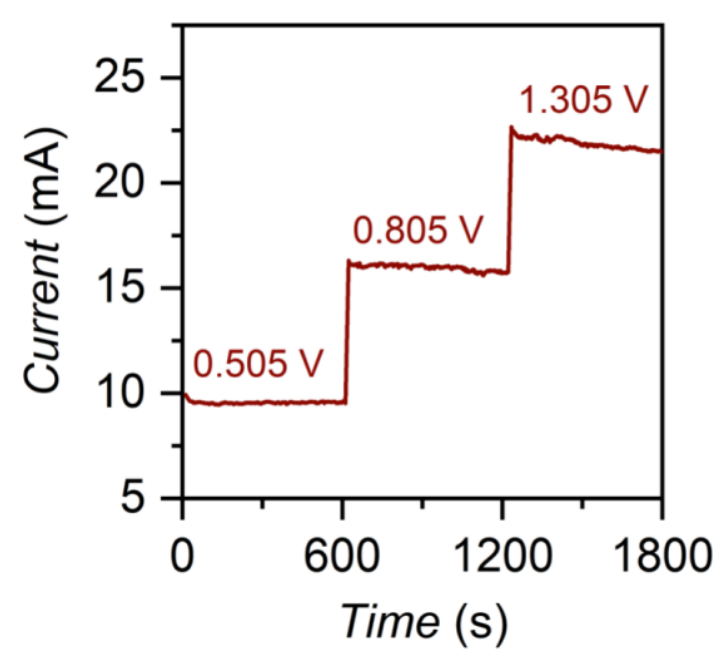

b)

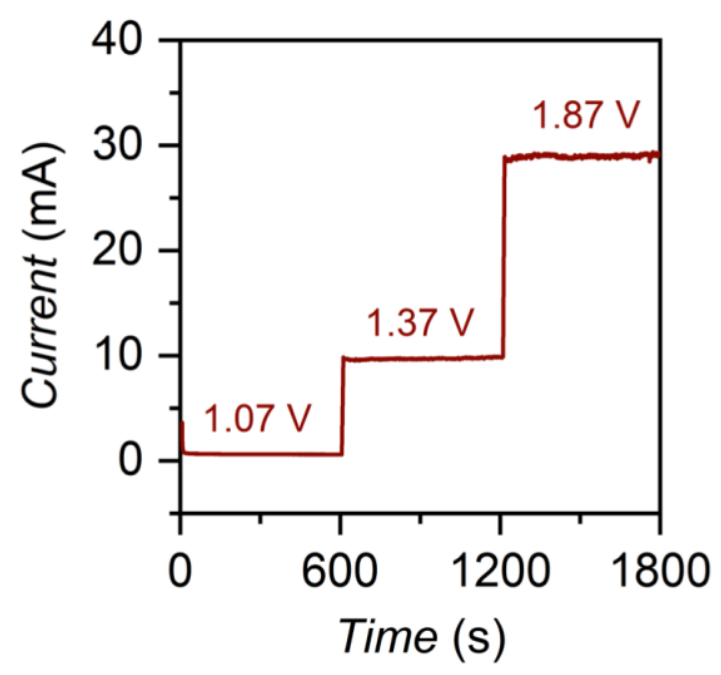

Figure S9. Three potential anodization of the $\mathrm{CoO}_{\mathrm{x}} \mid \mathrm{FTO}_{\text {thick }}$ anode (a) and the $\mathrm{CoO}_{\mathrm{x}} \mid \mathrm{FTO}_{\text {thin }}$ anode (b). Potentials are reported versus NHE. Anodization was performed in $0.1 \mathrm{M} \mathrm{KOH}$ with a Pt counter electrode and a leakless $\mathrm{Ag} / \mathrm{AgCl}$ reference electrode. The uncompensated resistance $\left(R_{u}\right)$ for both samples was $\sim 20 \Omega$. No IR correction was applied. 
a)

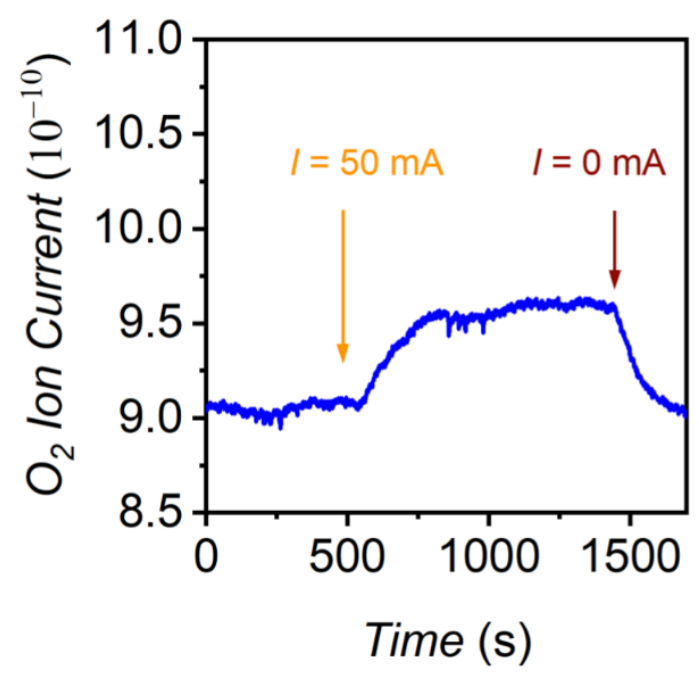

b)

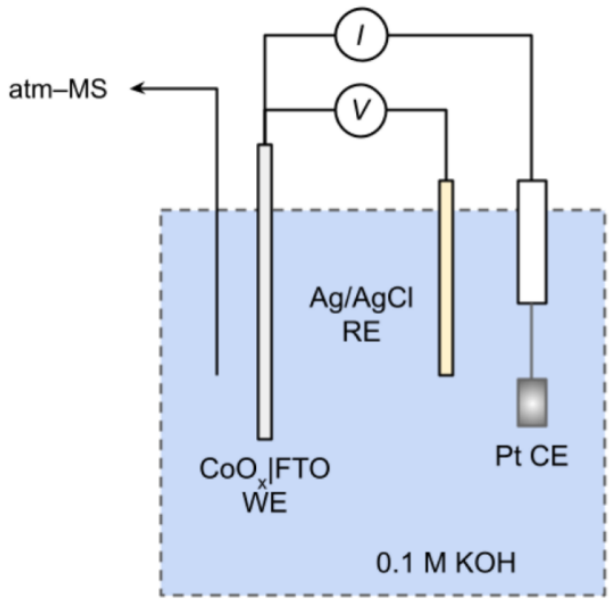

Figure S10. The atm-MS response as a function of time during electrolysis (a) and the experimental setup used (b). $\mathrm{O}_{2}$ ion current corresponds to the atm-MS response at $\mathrm{m} / \mathrm{z}=16$.
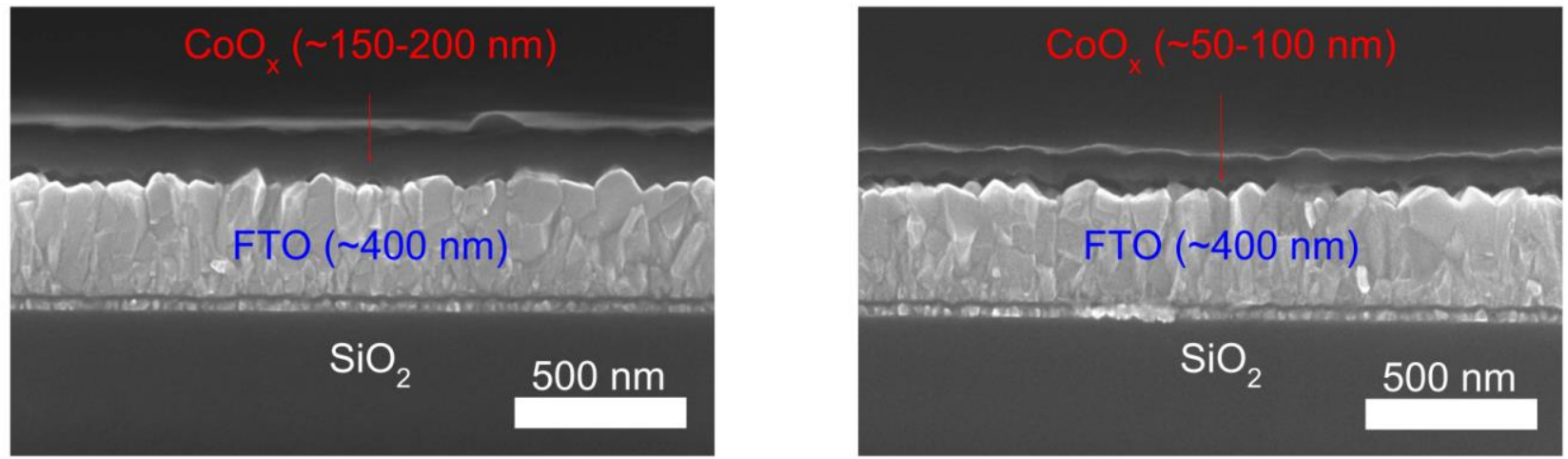

Figure S11. Cross-sectional scanning electron microscopy (SEM) images of (a) the $\mathrm{CoO}_{\mathrm{x}} \mid \mathrm{FTO}_{\text {thick }}$ anode and (b) $\mathrm{CoO}_{\mathrm{x}} \mid \mathrm{FTO}_{\text {thin }}$ anode. 
a)

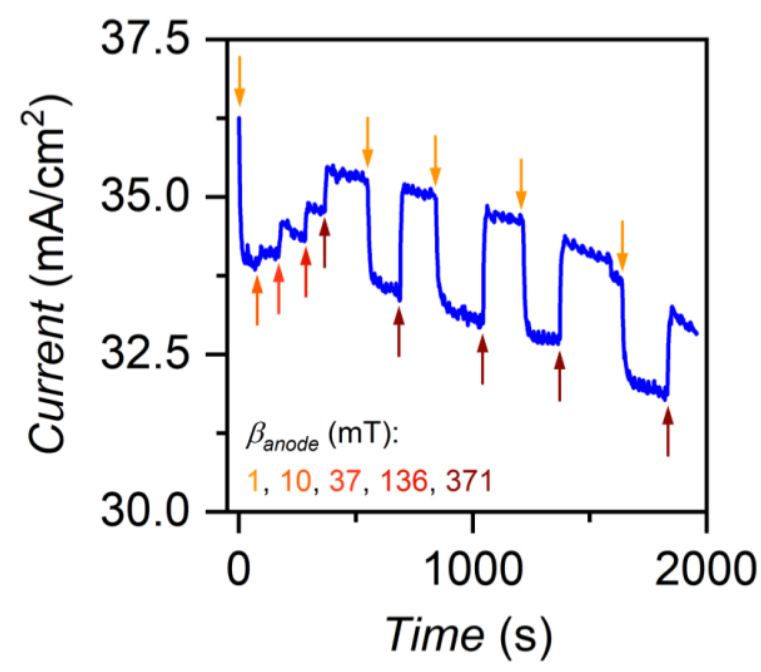

b)

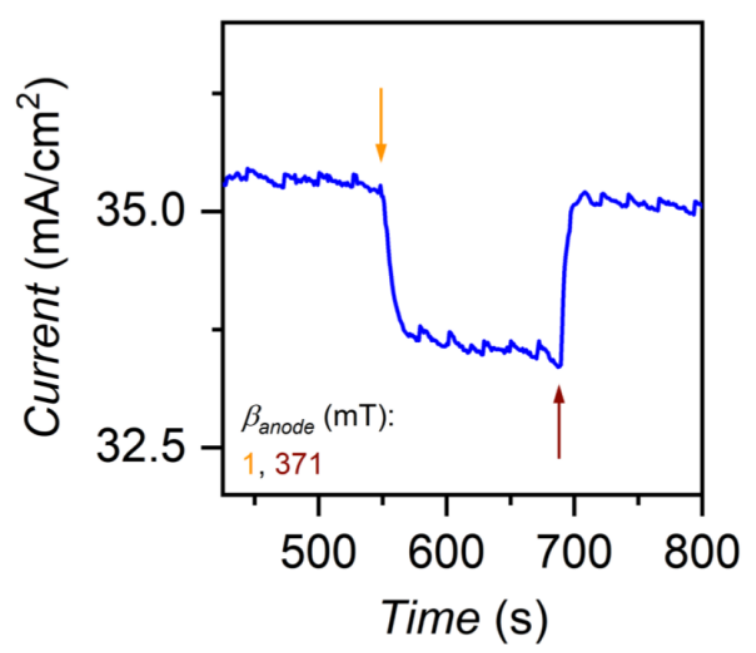

Figure S12. a) Potentiostatic bulk electrolysis with a $\mathrm{CoO}_{\mathrm{x}} \mid \mathrm{FTO}_{\text {thick }}$ at $1.5 \mathrm{~V}$ vs. $\mathrm{NHE}\left(R_{u} \cong 20 \Omega\right.$, no IR correction applied) with $\beta_{\text {anode }}$ in the inset. Measurements were performed in $0.1 \mathrm{M} \mathrm{KOH}$ with a Pt counter electrode and a leakless $\mathrm{Ag} / \mathrm{AgCl}$ reference electrode. b) A magnified view illustrating the timescale of the onset and offset of the magnetic enhancement.

a)

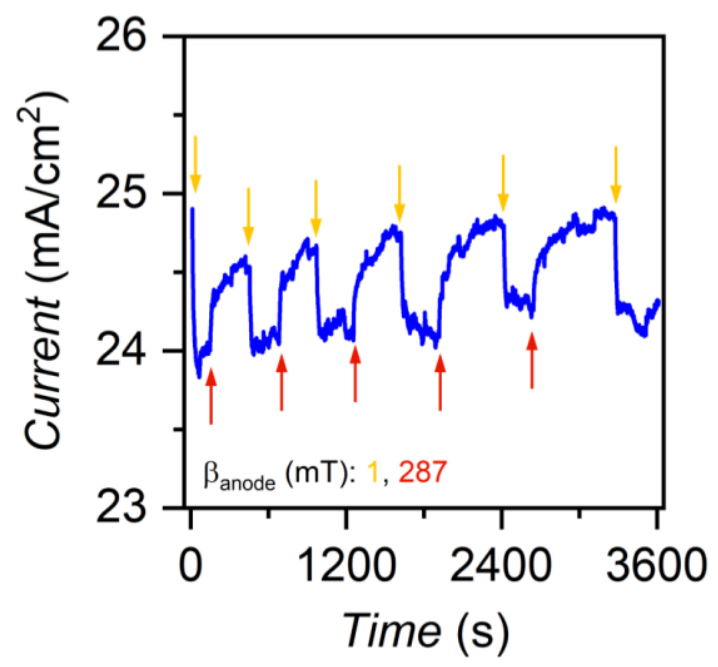

b)

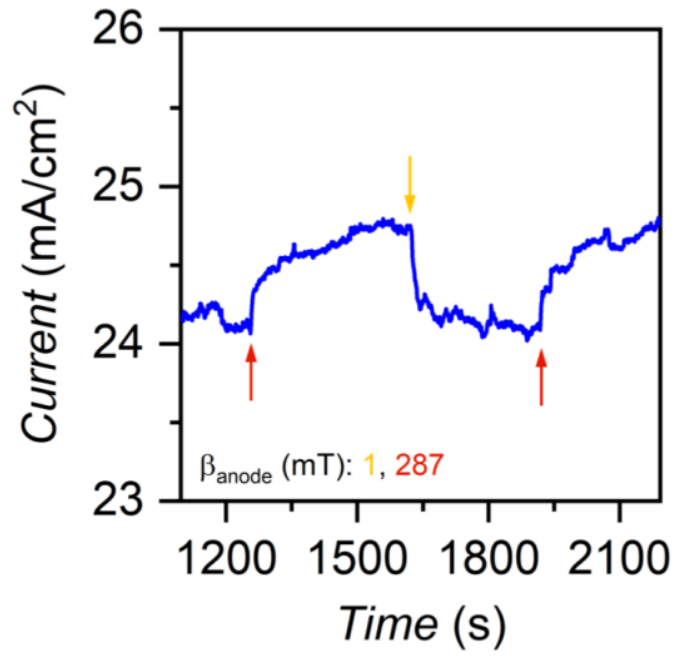

Figure S13. a) Potentiostatic bulk electrolysis with a $\mathrm{CoO}_{\mathrm{x}} \mid \mathrm{FTO}_{\text {thin }}$ at $1.5 \mathrm{~V}$ vs. $\mathrm{NHE}\left(R_{u} \cong 20 \Omega\right.$, no IR correction applied) with $\beta_{\text {anode }}$ in the inset. Measurements were performed in $0.1 \mathrm{M} \mathrm{KOH}$ with a Pt counter electrode and a leakless $\mathrm{Ag} / \mathrm{AgCl}$ reference electrode. b) A magnified view illustrating the timescale of the onset and offset of the magnetic enhancement. 
a)

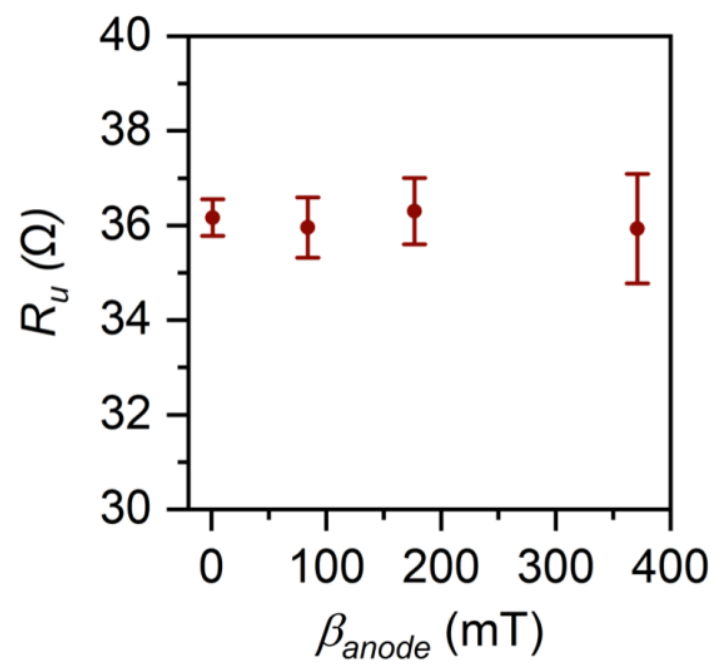

b)

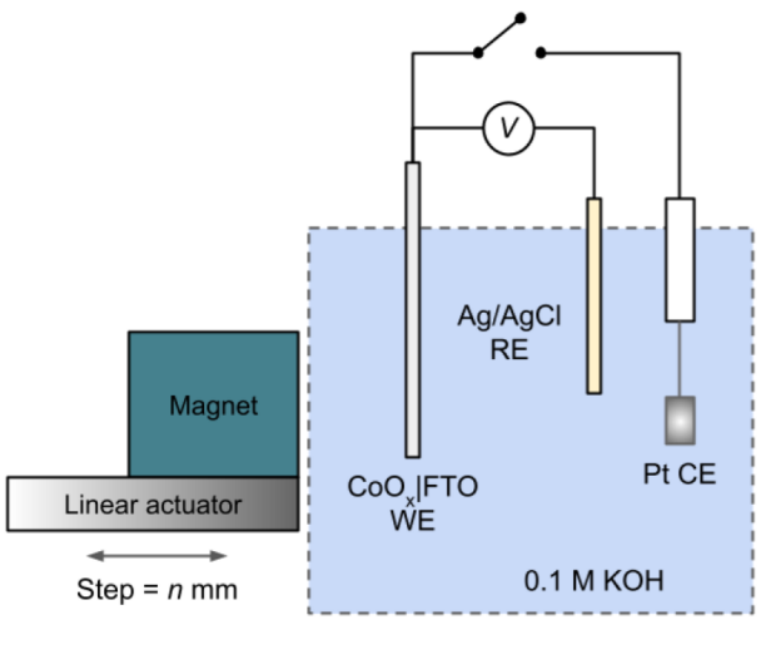

Figure S14. The uncompensated resistance $\left(R_{u}\right)$ of the electrochemical cell as a function of $\beta_{\text {anode }}$. Measurements were performed in $0.1 \mathrm{M} \mathrm{KOH}$ with a $\mathrm{Pt}$ counter electrode and a leakless $\mathrm{Ag} / \mathrm{AgCl}$ reference electrode.

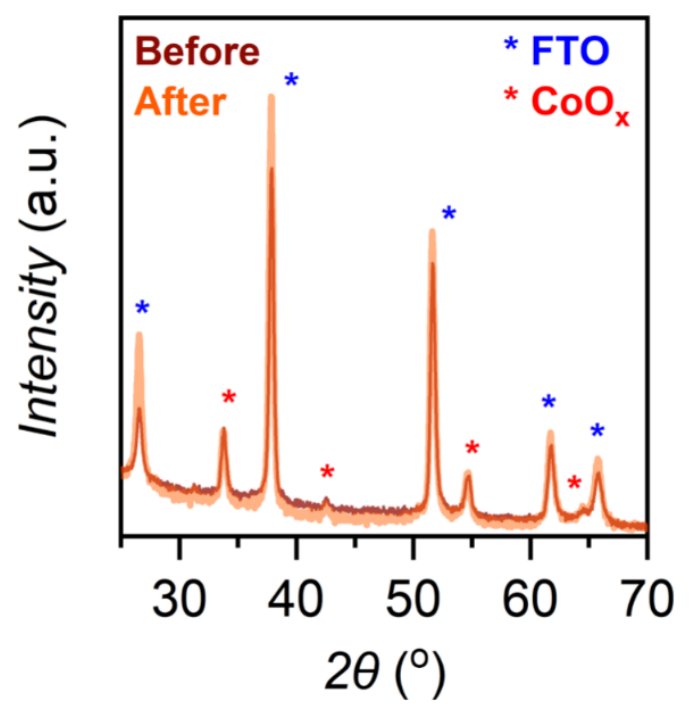

Figure S15. XRD spectrum of the CoOx|FTO electrode before (dark red) and after (pale orange) electrolysis in $0.1 \mathrm{M} \mathrm{KOH}$ at $50 \mathrm{~mA} \cdot \mathrm{cm}^{-2}$ for $1 \mathrm{~h}$. 

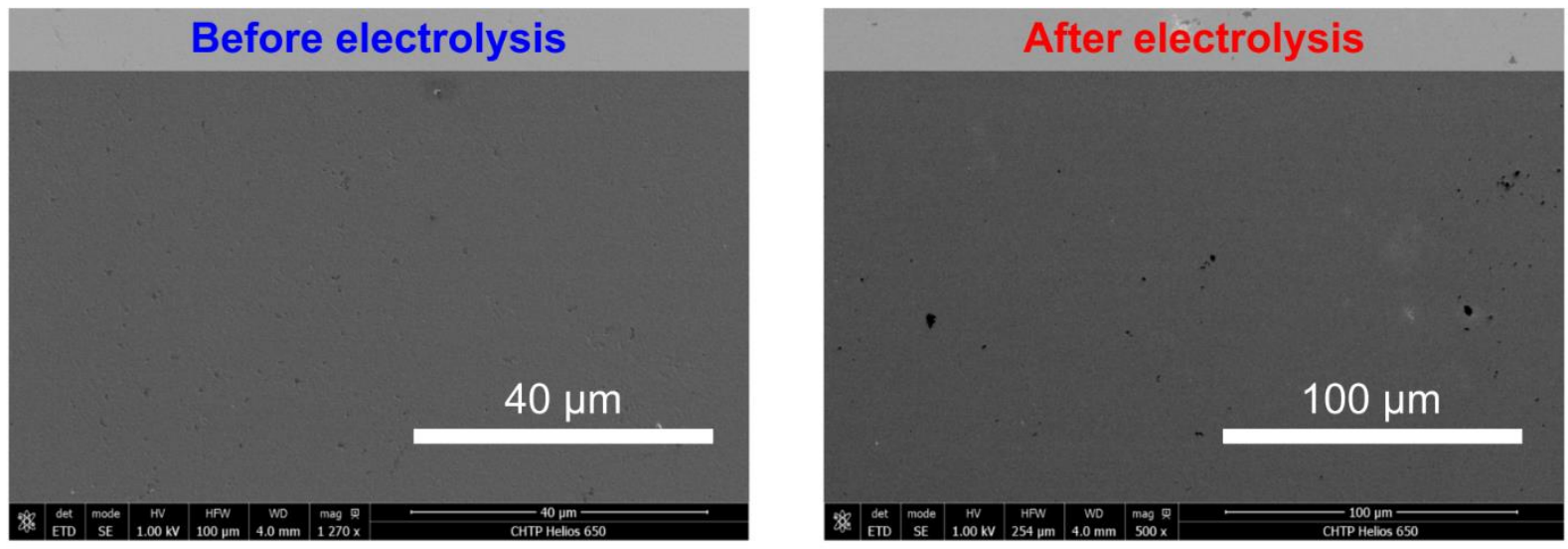

Figure S16. SEM images of the $\mathrm{CoO}_{\mathrm{x}} \mid \mathrm{FTO}$ electrode before (a) and after (b) electrolysis in $0.1 \mathrm{M} \mathrm{KOH}$ at $50 \mathrm{~mA} \cdot \mathrm{cm}^{-2}$ for $1 \mathrm{~h}$.

a)

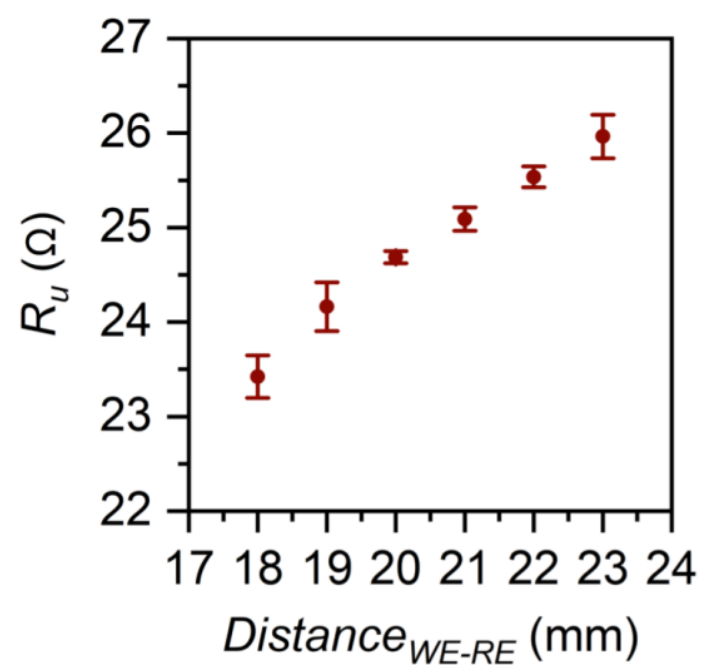

b)

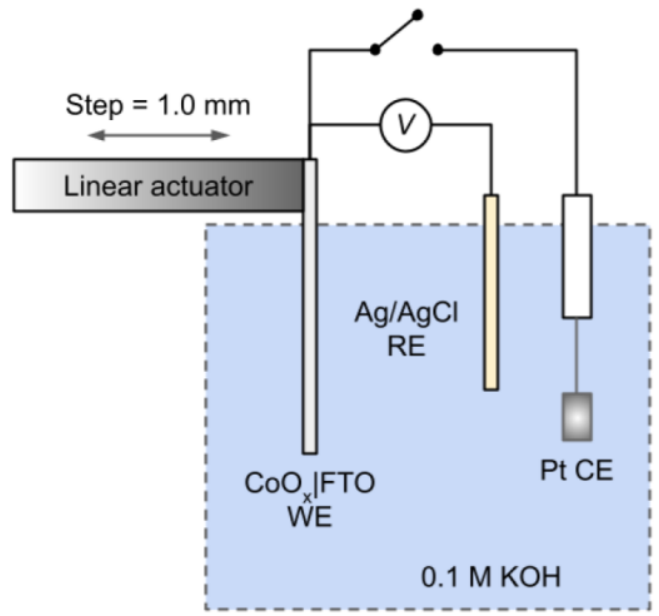

Figure S17. The uncompensated resistance $\left(R_{u}\right)$ as a function of distance between the $\mathrm{CoO}_{\mathrm{x}} \mid \mathrm{FTO}_{\text {thin }}$ anode and the leakless $\mathrm{Ag} / \mathrm{AgCl}$ reference. The $\mathrm{CoO}_{\mathrm{x}} \mid \mathrm{FTO}$ anode was mounted on a linear actuator that was used to control the position to within $x \mathrm{~mm} \pm 0.01 \mathrm{~mm}$ relative to the reference electrode. Measurements were performed in $0.1 \mathrm{M} \mathrm{KOH}$ with a Pt cathode. Error bars represent the standard deviation of triplicate measurements performed on a single sample. 
a)

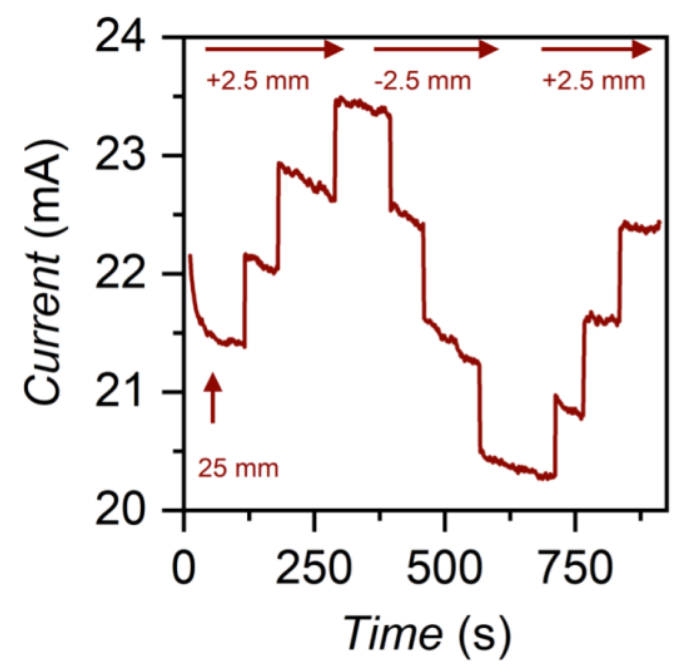

b)

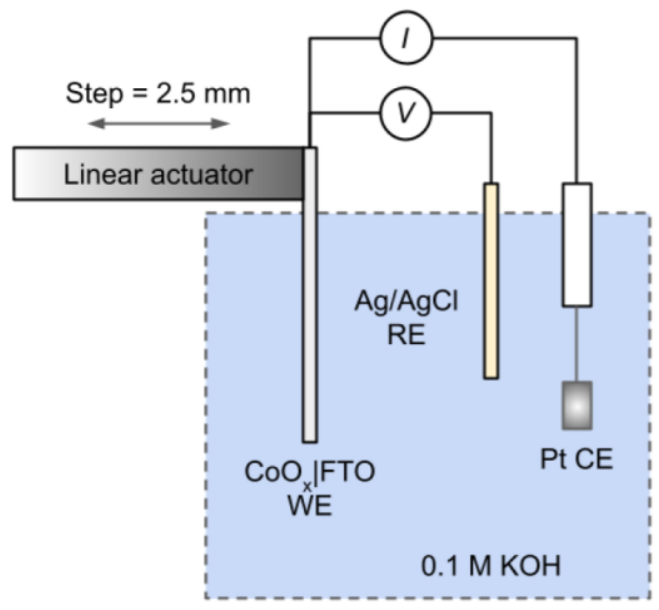

Figure S18. The potentiostatic current response at a voltage of $1.6 \mathrm{~V}$ vs. $\mathrm{Ag} / \mathrm{AgCl}$ as a function of the distance from the $\mathrm{CoO}_{\mathrm{x}} \mid \mathrm{FTO}$ anode from the leakless $\mathrm{Ag} / \mathrm{AgCl}$ reference electrode. The $\mathrm{CoO}_{\mathrm{x}} \mid \mathrm{FTO}$ anode was mounted on a linear actuator that was used to control the position to within $x \mathrm{~mm} \pm 0.01 \mathrm{~mm}$ relative to the reference electrode. Measurements were performed in $0.1 \mathrm{M} \mathrm{KOH}$ with a Pt cathode. No IR correction was applied.

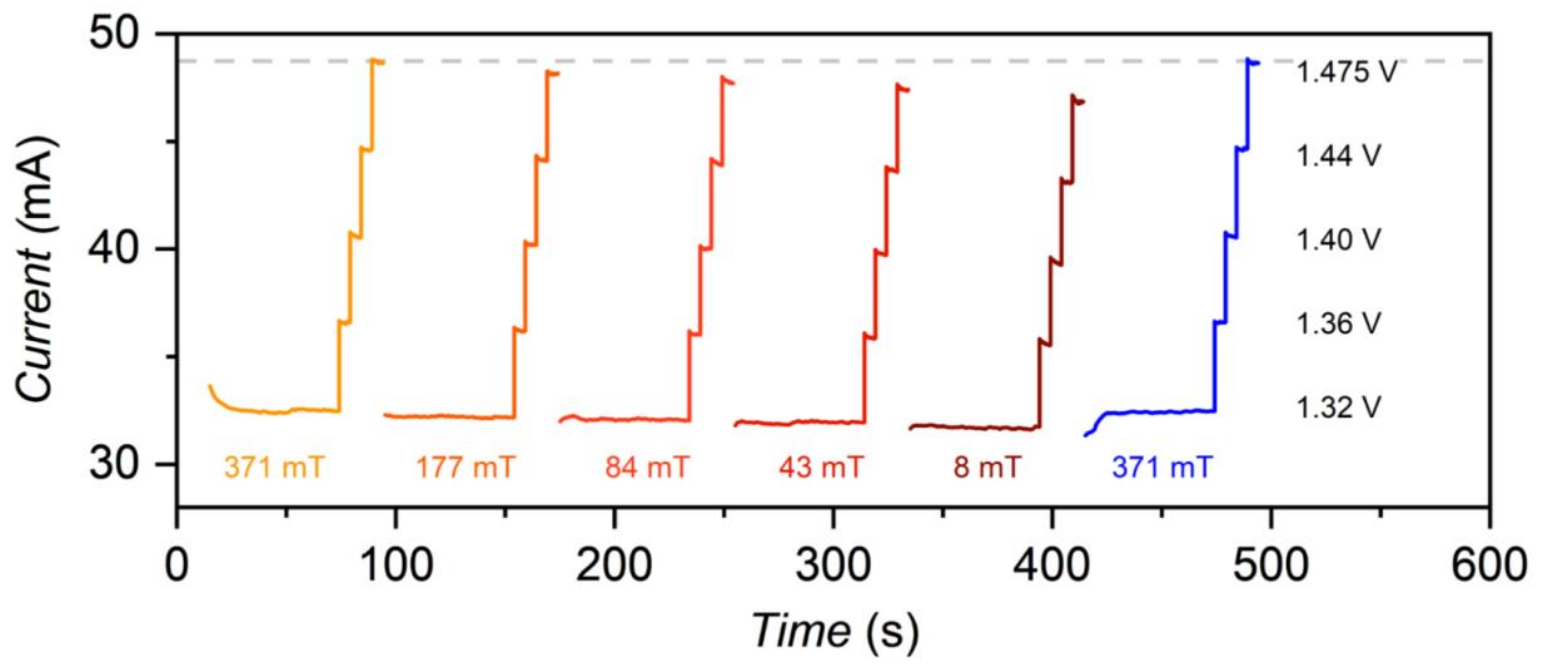

Figure S19. A potentiostatic polarization series used to construct the Tafel plots. The potential (V) is measured vs. NHE. The blue line represents a recursive data point used to verify that the film exfoliation was negligible during data collection. 


\section{References}

1. Bard, A. J., Faulkner, L. R. \& Others. Fundamentals and applications. Electrochemical Methods 2 , 580-632 (2001).

2. Stevens, M. B. et al. Measurement Techniques for the Study of Thin Film Heterogeneous Water Oxidation Electrocatalysts. Chem. Mater. 29, 120-140 (2017).

3. Anantharaj, S. et al. Precision and correctness in the evaluation of electrocatalytic water splitting: revisiting activity parameters with a critical assessment. Energy Environ. Sci. 11, 744-771 (2018).

4. Ghosh, S., Bloom, B. P., Lu, Y., Lamont, D. \& Waldeck, D. H. Increasing the Efficiency of Water Splitting through Spin Polarization Using Cobalt Oxide Thin Film Catalysts. J. Phys. Chem. C 124, $22610-22618$ (2020).

5. Yoon, Y., Yan, B. \& Surendranath, Y. Suppressing Ion Transfer Enables Versatile Measurements of Electrochemical Surface Area for Intrinsic Activity Comparisons. J. Am. Chem. Soc. 140, 2397-2400 (2018). 